\title{
UM CAMINHAR NA APROXIMAÇÃO DA ENTREVISTA FENOMENOLÓGICA
}

Sonia Mara Faria Simões* Ívis Emília de Oliveira Souza**

SIMÕES, S.M.F.; SOUZA, I.E. de O. Um caminhar na aproximação da entrevista fenomenológica. Rev.Latinoam.enfermagem. Ribeirão Preto, v. 5, n. 3, p. 13-17, julho 1997.

O presente trabalho tem por objetivo descrever minha vivência na aproximação à entrevista fenomenológica. A trajetória foi conduzida em quatro momentos, buscando adequar aspectos como o ambiente físico, a estratégia de aproximação às depoentes, a questão norteadora e a técnica de obtenção dos depoimentos. A abordagem sujeito-pesquisador ao sujeito-pesquisado indicou ajustes na utilização da técnica e redirecionou meu caminhar pessoal e profissional.

UNITERMOS: fenomenologia, entrevista fenomenológica, método de pesquisa

\section{INTRODUÇÃO}

Meu caminhar na elaboração da dissertação de Mestrado em Enfermagem da E.E.A.N. proporcionou momentos de reflexões profundas e enriquecedoras.

A delimitação da temática a estudar não foi difícil, uma vez que faz parte da minha vivência na aréa da Obstetrícia e experiência na Enfermagem Obstétrica.

Minha atividade no Centro Obstétrico de uma Maternidade do Serviço Público Federal possibilitou-me observar as mais variadas posturas da mulher frente ao seu processo parturitivo. Muitas vezes, a parturiente internada apresenta sinais -como rosto pálido ou muito corado, mãos úmidas ou trêmulas, voz baixa e insegura que, em conjunto, mostram a tensão interior que vivencia.

Com o desenvolver do trabalho de parto, percebem-se expressões de angústia, medo, inquietação, indiferença, que se acentuam na medida em que o próprio desconforto da parturição evolui. Estes comportamentos e/ou atitudes demonstrados pela mulher durante o trabalho de parto provocaram-me um pensar no sentido do que significa esta vivência para ela. Refleti, ainda, que a parturiente encontra-se sozinha, afastada de seu mundo, no cotidiano hospitalar onde o "parir" é uma atividade rotineira e até impessoal dentro do contexto institucional. Assim, o meu interrogar se concretizou em buscar a compreensão do significado da vivência do trabalho de parto para a mulher que pariu.

Considerando minha inexperiência como investigadora, surgiu a dificuldade na escolha de uma metodologia pertinente a esse objeto de estudo. As disciplinas cursadas no $1^{\circ}$ semestre de 1993 proporcionaram-me leituras e reflexões sobre os vários métodos de investigação e conduziram-me a caracterizar minha pesquisa como qualitativa, pelo fato desta metodologia buscar uma compreensão particular daquilo que se estuda. É o interrogar do "mundo ao redor" (MARTINS \& BICUDO) ${ }^{4}$.

$\mathrm{Na}$ busca de uma modalidade de pesquisa qualitativa que me auxiliasse e fosse adequada ao objeto do estudo, aproximei-me da fenomenologia, porque está voltada para o estudo da realidade social enquanto vivida na sua vida cotidiana (CAPALBO $)^{2}$.

TRIVIÑOS ${ }^{6}$ refere que a fenomenologia dá ênfase ao "significado" que as pessoas dão às coisas e à vida. Os significados são obtidos através das descrições dos depoimentos e, para tanto, deverá ser utilizada a entrevista na modalidade fenomenológica como instrumento de obtenção dos mesmos.

A entrevista nesta abordagem é considerada por MARTINS \& BICUDO 4 como um "encontro social”, com características peculiares como a empatia e a intersubjetividade, onde ocorre a penetração mútua de percepções. É colocar-se no lugar do outro.

CARVALHO $^{3}$ afirma que uma entrevista fundamentada na metodologia fenomenológica busca uma linguagem que seja a "fala originária", "fala" esta que possibilita a mediação com o outro e a comunicação com o mundo.

Nesta entrevista MARTINS \& BICUDO ${ }^{4}$ referem que é impossível seguir regras.

\footnotetext{
* Professor do Departamento de Fundamentos de Enfermagem e Administração da UFF e Doutoranda da EEAN-UFRJ

** Professor Doutor do Departamento de Enfermagem Materno-Infantil da EEAN-UFRJ
} 
Assim, já com o projeto de dissertação de mestrado "O ser parturiente: um enfoque vivencial" (SIMÕES) ${ }^{5}$ aprovado e estando na fase de obtenção dos depoimentos, vi-me diante da dificuldade de conduzir a entrevista fenomenológica, pelas particularidades próprias desta forma de aproximação, acima mencionadas.

Compreendi que, antes de iniciar a aproximação à entrevista fenomenológica, deveria buscar o entendimento dos fundamentos da fenomenologia, a fim de conduzir meu estudo com rigor, seriedade e propriedade e chegar a um novo conhecimento (BOEMER) ${ }^{1}$.

Neste sentido, durante dois meses, percorri a trajetória em direção à compreensão da metodologia de investigação fenomenológica e a que ela se propõe. Houve empenho em encontrar trabalhos científicos que contribuíssem para entender como ocorre a aproximação sujeito-pesquisador ao sujeito-pesquisado, mas o relato deste encontro é descrito geralmente sem especificar as dificuldades encontradas pelo pesquisador.

A apreensão dos pontos a serem observados pelo investigador no desenvolvimento da entrevista na modalidade fenomenológica, foi obtida em CARVALHO $^{3}$, obra onde a autora, sob a ótica do Serviço Social, trabalha a temática em três capítulos, abordando as características peculiares desta técnica. Destaca a necessidade de percepção do pesquisador no sentido de: 1. ver e observar, sem estar fechado em uma perspectiva causal; 2. interpretar compreensivamente a linguagem do cliente e a percepção dessa linguagem como veículo de significações; e 3. Perceber o gesto do cliente em seu movimento.

Conseqüentemente, as leituras realizadas sobre as especificidades da entrevista na abordagem fenomenológica exigiriam de mim um posicionamento inteiramente voltado para este fim. Caminhei, então, em busca de desvelar o sentido da vivência do trabalho de parto para a mulher e a entrevista realizada segundo essa abordagem constituiu-se em um recurso básico para a condução da investigação. Assim, com este texto proponho-me a explicitar ao leitor a minha trajetória de aproximação a esse referencial para conduzir entrevistas.

\section{OBJETIVO}

Diante das dificuldades encontradas, pareceu-me oportuno desenvolver um texto com o objetivo de descrever minha vivência na aproximação da entrevista fenomenológica. Acredito que este relato de experiência, possibilitará ajuda aos pesquisadores na área da fenomenologia e da enfermagem.

\section{METODOLOGIA}

O local escolhido para a minha vivência de aproximação à entrevista fenomenológica foi a maternidade de uma instituição do Serviço Público Federal, onde desenvolvo atividades profissionais.

\section{Reflexões sobre o cenário de aproximação sujeito- pesquisador ao sujeito-pesquisado}

Após permissão da instituição para desenvolver as atividades de pesquisa, e tendo conhecimento prévio sobre a rotina de atendimento do setor, julguei adequado decidir sobre pontos que pudessem limitar ou facilitar minha atuação como investigadora.

Tendo em vista o objeto de estudo investigado, o significado da vivência do trabalho de parto para a mulher, decidi que as depoentes seriam as mulheres em estado puerperal, por já terem vivido todo o processo da parturição. Estabeleci que faria a aproximação às puérperas à tarde, período considerado mais tranquiilo, no qual a assistência basicamente é dada pela equipe de enfermagem.

Como estratégia de obtenção dos depoimentos optei por utilizar um jaleco e não uniforme na apresentação às depoentes, a fim de que as clientes não confundissem os papéis de pesquisadora e profissional. Acreditei ser importante desenvolver as entrevistas sentada, pois percebo que esta postura parece falar da disposição "para ouvir".

Desejei conduzir os encontros sujeitopesquisador -sujeito-pesquisado anotando no momento da entrevista apenas o essencial, o individual e, logo em seguida, transcrevê-los, buscando a alternativa de memorização das falas e gestos das depoentes. O diário de campo serviria para registro dos depoimentos, de meus passos e percepções e teria em sua primeira página,a questão norteadora da entrevista, "O que significou, para você, a experiência do trabalho de parto?”. Sua confecção se daria, após o término das visitas ao hospital, em minha residência. Na leitura de cada depoimento, deveria penetrar no mundo-vida das puérperas, almejando a compreensão da sua vivência do trabalho de parto.

\section{Momentos vivenciados na trajetória de aproximação sujeito-pesquisador ao sujeito-pesquisado}

Após as decisões citadas acima percebi que a condução na entrevista fenomenológica abrangeria o lidar com aspectos essenciais, tais como: o ambiente físico disponível para o encontro, a estratégia de aproximação às depoentes, a adequação da questão norteadora e a técnica de obtenção dos depoimentos. Observei que estes aspectos, devidamente interligados e direcionados a 
atender meu objeto de estudo, poderiam fornecer descrições repletas de significados sobre a vivência do trabalho de parto.

Embora o método fenomenológico não comporte passos, etapas, creio ter percorrido a trajetória na aproximação da entrevista fenomenológica em quatro momentos, ora priorizando uns fatores, ora outros.

Assim, no primeiro momento, minha preocupação era encontrar um ambiente físico propício para o "encontro social". Como conseguir a empatia e chegar à intersubjetividade, se na Clínica Obstétrica não havia um local reservado para desenvolver as entrevistas?. Eu acreditava que a enfermaria não seria conveniente, uma vez que se constituíam de 6 leitos cada, dispostos de forma a não se ter privacidade.

Como conduta de aproximação às puérperas resolvi fazer minha apresentação pessoal e profissional na enfermaria e, em seguida, esclarecer a proposta de estudo enfatizando que buscava, através das falas, a compreensão da vivência do trabalho de parto na fase de dilatação.

Estes pré-julgamentos sobre a situação a ser encontrada levaram-me a optar por convidar as mulheres a falar de sua experiência em um banco localizado na entrada do setor, no corredor, tentando observar se este ambiente seria apropriado para a entrevista. Neste momento,a questão norteadora seria lançada.

Após a transcrição e leitura dos depoimentos obtidos e de minhas percepções no diário de campo, concluí que os passos seguidos não me levaram a perceber o modo de ser das depoentes. O local utilizado para a entrevista e a estratégia de aproximação não favoreceram o encontro empático entre sujeito-pesquisador e sujeitopesquisado. As puérperas revelaram incompreensão da pergunta formulada, sendo necessário especificar o objeto de investigação.

Estes pontos não definidos conduziram-me a voltar à bibliografia referente à abordagem fenomenológica e ao meu pré-reflexivo, buscando um caminhar mais pertinente a este método de pesquisa.

Portanto, o segundo momento de minha trajetória de aproximação à entrevista fenomenológica foi marcado por mudanças, tais como: o local utilizado para o encontro seria a enfermaria onde estivessem as puérperas, iniciando o diálogo através da oportunidade que surgisse no momento. Somente ao perceber a postura receptiva investiria na minha identificação pessoal e esclarecimento sobre o objeto de estudo. Em seguida, lançaria a questão norteadora reformulada "O que foi para você, vivenciar a fase de dilatação do trabalho de parto?", para a cliente que estivesse manifestando disposição para descrever sua vivência.

Esta proposta foi contemplada durante a tarde em que permaneci no setor de Obstetrícia.

Ao ler a experiência vivenciada descrita no diário de campo, compreendi que a nova estratégia de abordagem às puérperas facilitou a integração sujeitopesquisador - sujeito-pesquisado; todavia, houve novamente a necessidade de explicitar o termo "vivenciar" utilizado na questão norteadora, pois o mesmo não foi entendido por várias depoentes.

Quanto à técnica de obtenção de depoimentos, observei minha dificuldade em dar continuidade à transcrição das falas, o que me fez decidir por usar o gravador nas próximas entrevistas, desde que houvesse o consentimento das depoentes.

Assim, em outra visita ao hospital para implementar o terceiro momento da condução, na entrevista fenomenológica, buscava aprimorar a forma de aproximação às puérperas. Compreendi que não deveria determinar qual a depoente a falar e sim aguardar aquela que se mostrasse "disposta para". Também iniciei a gravação, em fita cassete, das novas entrevistas (após aceite das mulheres) como processo facilitador na obtenção das vivências singulares. Nesta oportunidade, trabalharia com a questão norteadora modificada: "O que significou, para você, a experiência passada na Sala de Pré-Parto?".

Posteriormente, a análise dos depoimentos obtidos e de minhas percepções levaram-me a acreditar estar próxima à compreensão do método da entrevista fenomenológica uma vez que os significados das falas originárias começaram a se desvelar para mim. Entretanto, era necessário repensar sobre a interrogativa adequada à descrição de meu objeto de estudo, uma vez que novamente a pergunta formulada não foi explícita. Voltei aos fundamentos da metodologia de pesquisa fenomenológica e acabei elaborando a questão norteadora para: "O que foi, para você, a experiência passada na Sala de Pré-Parto?"

A avaliação do emprego do gravador nas entrevistas mostrou ser necessária a sua instalação mais próxima à depoente, além da checagem do funcionamento adequado, a fim de não se perder vivências singulares. Neste sentido, já com a estratégia de aproximação às depoentes definida, tendo um agir como investigadora livre de pressupostos, dispus-me a vivenciar o quarto momento do encontro sujeito-pesquisador ao sujeitopesquisado, basicamente para adequação da pergunta elaborada e aprimoramento da técnica de gravação.

Foram obtidos 16 depoimentos, que proporcionaram o clareamento das peculiaridades da entrevista fenomenológica, além do desvelamento de sentidos na vivência do trabalho de parto.

\section{APREENSÃO} VIVENCIADA

EXPERIÊNCIA

Considero importante destacar que o meu 
caminhar de aproximação à entrevista fenomenológica não foi apenas didático, mas contribuiu para o meu próprio crescimento pessoal e profissional. Despertou reflexões sobre o tipo de abordagem que venho desenvolvendo à cliente durante a atuação profissional.

Na realidade, é difícil não utilizar uma atitude de decisão perante a paciente. O "dispor para", o "deixar que" o próprio cliente opine, decida e até se recuse "a fazer" não faz parte da rotina de assistência institucional e, muito menos, de nossa própria aceitação enquanto profissional prestador de cuidados de saúde.

Após esta trajetória, percebo ainda o porque de não haver descrito na literatura de pesquisa fenomenológica a "fórmula" ou os "passos" como guia para se chegar às peculiaridades deste tipo de entrevista. Agora entendo que os questionamentos iniciais quanto ao modo de proceder, às inquietações e os préjulgamentos existem em cada pesquisador que se dispõe a desenvolver estudo na abordagem fenomenológica.

Compreendi que importa a cada investigador "buscar" a melhor forma de aproximação aos seus depoentes, levando em consideração o alcance dos objetivos propostos e aspectos como o ambiente físico propício ao "encontro social", as particulariedades da clientela escolhida, a adequação da questão norteadora e da técnica de obtenção dos depoimentos. Estes fatores devidamente interligados e ajustados conduzem a descrições singulares do objeto de estudo proposto e levam a um novo conhecimento, a um desvelar de facetas do fenômeno aos olhos de quem o vivencia.

A condução do pesquisador na entrevista fenomenológica é gradativa e necessária ao investigador, percebendo-se por onde começar, o que mais incomoda ou impede o prosseguir e o que fazer para superar as dificuldades. Esta trajetória é mais amena quando o pesquisador tem seu objeto de estudo definido de forma consistente e clara.

Esta vivência de aproximação conduziu-me à apreensão de pontos importantes, como:

- Meu pressuposto de ser a enfermaria um local inadequado para a obtenção dos depoimentos foi falho. Percebi, ao contrário, que este lugar funcionava como um agente facilitador para as entrevistas, pois a fala de uma puérpera criava “disposição para” em outras clientes, mostrando um desvelar de experiências vivenciadas na internação hospitalar. A fala originária de cada depoente penetrava o mundo-vida da outra e levava o grupo à intersubjetividade.

- Percebi que a busca para obter descrições singulares implica em não determinar qual a depoente a ser abordada, mas sim esperar aquela que se mostre como reveladora de meu objeto de estudo.

- Quanto à minha preocupação em definir os papéis de profissional e pesquisadora, relato que não há como separá-los. O lado profissional está imanente, porém o pesquisador deve estar atento, a fim de não prejudicar sua trajetória de investigação. Pude observar que durante a abordagem de aproximação às depoentes utilizei as oportunidades surgidas para diálogo, enquanto profissional da enfermagem (respostas às indagações feitas), mas no momento em que lançava a questão norteadora, preocupava-me basicamente em assumir o papel de investigadora, buscando alcançar descrições singulares do objeto de estudo investigado. Os esclarecimentos necessários eram trabalhados ao término da entrevista. Assim, houve mudança de minha postura profissional, já não era mais a "sabedora das coisas", mas esperava pela participação da cliente, pela reflexão sobre as próprias dúvidas. Foi um movimento de procurar saber do cliente, e não sobre o cliente.

- A adequação da questão norteadora revelou a importância de se elaborar uma interrogativa clara para o entendimento das depoentes e alcançar a descrição das vivências singulares do trabalho de parto.

- A decisão de gravar os encontros mostrou-me que, além das depoentes não ficarem inibidas diante do aparelho (microfone interno), proporcionava-me maior liberdade para atentar às falas originárias, penetrar o mundo das clientes e impregnar-me por sua linguagem e gestos.

Finalmente, este caminhar de aproximação sujeito-pesquisador ao sujeito-pesquisado é etapa que requer tempo, reflexões constantes, "disposição para". Não deve ser direcionado pela quantidade das entrevistas realizadas, mas pela busca da qualidade, na qual os depoimentos empáticos possam levar à compreensão do fenômeno vivido investigado e não à explicação.

\section{AN APPROACH TO PHENOMENOLOGICAL INTERVIEW}

The purpose of this study is to describe my experiences about the phenomenological interview. It was developed in four moments, in order to adequate physical environment aspects, strategies of approaching the interviewers, the orientation question and the techniques to obtain the statements. The focus on researcher-subject/researched-subject has indicated adjustments in the utilization of the techniques and reoriented my person and professional development. 
UN CAMINAR EN LA APROXIMACIÓN A LA ENTREVISTA FENOMENOLÓGICA

El presente trabajo tiene como objetivo describir mi vivencia en la aproximación a la entrevista fenomenológica, en la trayectoria fue conducida en cuatro momentos, buscando ajustar aspectos como el ambiente físico, la estrategia de aproximación a las declarentes, la pregunta orientadora y la técnica de obtención de las hipótesis. El abordage sujeto-investigador al sujetoinvestigado indicó ajustes en la utilización de la técnica y redireccionó mi caminar personal y profesional.

TÉRMINOS CLAVES: fenomenología, entrevista fenomenológica, método de la investigación

\section{REFERÊNCIAS BIBLIOGRÁFICAS}

01. BOEMER, M. R. A condução de estudos segundo a metodologia de investigação fenomenológica. Rev.latino-am.enfermagem, Ribeirão Preto, v. 2 , n.1, p. 83-94, 1994.

02. CAPALBO, C. Algumas considerações sobre a fenomenologia que podem interessar ao Serviço Social. Supl. de Debates Sociais, n.8, agosto/ 1980.

03. CARVALHO, A. de S. Metodologia da entrevista: uma abordagem fenomenológica. Rio de Janeiro: Agir, 1991.
04. MARTINS, J.; BICUDO, M.A.V. A pesquisa qualitativa em psicologia: fundamentos e recursos básicos. São Paulo: EDUC, 1989.

05. SIMÕES, S. M.F. O Ser Parturiente: um enfoque vivencial. Projeto de Dissertação de Mestrado em Enfermagem. Universidade Federal do Rio de Janeiro, Escola de Enfermagem Anna Nery. Coordenação de Pós-Graduação e Pesquisa. Rio de Janeiro, março 1994.

06. TRIVIÑOS, A. N.S. Introdução à pesquisa em ciências sociais: a pesquisa qualitativa em educação. São Paulo: Atlas, 1992. 